\title{
Friction stir welding of thin DH36 steel plate
}

\author{
N. A. McPherson*1, A. M. Galloway ${ }^{2}$, S. R. Cater ${ }^{3}$ and S. J. Hambling ${ }^{4}$
}

\begin{abstract}
A series of 4, 6 and $8 \mathrm{~mm}$ DH36 steel welds were produced using optimum conditions for friction stir welding (FSW). Comparator welds in the same thickness from the same plates were produced using a single sided single pass process submerged arc welds (SAW). This work was carried out to evaluate the mechanical properties of FSW material with a view to its possible application in a shipbuilding production process route.

Overall, the performance of the FSW material was superior to the SAW comparators. Areas such as distortion and fatigue were particularly positive in the FSW material. An $8 \mathrm{~mm}$ thick plate was also produced using two FSW passes, one from either side, and it was found to have superior toughness and fatigue performance when compared to the single sided $8 \mathrm{~mm}$ FSW material. Some of these benefits are thought to have originated from the internal overlap zone between the two passes.
\end{abstract}

Keywords: Friction stir welding, DH36 steel, Toughness, Fatigue, Distortion

\section{Introduction}

As the friction stir welding (FSW) process was progressively developed towards carbon steels such as those used in shipbuilding and linepipe, ${ }^{1}$ a number of studies $^{2-5}$ were carried out to evaluate the mechanical properties of the welded product. In addition, some work has been reported on the FSW of high carbon tool steel. $^{6}$ Much of this work gave a very mixed and inconsistent impression of the typical properties of FSW carbon steel. In addition, there appeared to be no data related to the fatigue properties of FSW carbon steel.

The initial work ${ }^{2}$ was based on a $0 \cdot 18 \mathrm{C}-0 \cdot 82 \mathrm{Mn}$ steel, which was $6.35 \mathrm{~mm}$ thick. The microstructure of this base material consisted of $20-30 \mu \mathrm{m}$ ferrite grains with smaller regions of pearlite. There was a stir zone and a heat affected zone (HAZ). The stir zone was characterised by a coarse ferrite lath and grain boundary ferrite structure in the mid thickness region, but at the surface in the region in contact with the tool, this was considerably finer. The HAZ displayed a progressive change in microstructure on moving from the stir zone to the outer HAZ. The change was from a coarse structure typical of the stir zone to a region showing progressively less pearlite degeneration. Although the hardness was higher in the stir zone and dropped off progressively through the HAZ, it was not at a level that would have caused any concern at all. Transverse tensile testing fractures were in the parent plate, demonstrating the superior tensile properties of the complete weld

${ }^{1}$ BAE Systems Surface Ships, Glasgow, UK

${ }^{2}$ Department of Mechanical and Aerospace Engineering, University of Southgate, Glasgow, UK

${ }^{3}$ TWI Technology Centre, Rotherham, UK

${ }^{4}$ BAE Systems Submarines, Barrow-in-Furness, UK

*Corresponding author, email norrie.mcpherson@baesystems.com region. However, no toughness testing was carried out on this material. A further study ${ }^{3}$ based on $6.4 \mathrm{~mm}$ thick DH36 steel only considered hardness and strength too. It is quoted that this steel had a similar composition to that in the previous study. ${ }^{2}$ However, the parent plate microstructures were quite different with coarse, nonbanded structure in the work of Lienert et al. ${ }^{2}$ and much finer and quite heavily banded structure in the study of Reynolds et al. ${ }^{3}$ The ferrite grain sizes were 25 and $4 \mu \mathrm{m}$ respectively, which is a significant difference. Microstructures were classed as containing bainite, martensite, untempered martensite and granular bainite, all of which would normally indicate a potentially high hardness structure. Compared to the previous work, ${ }^{2}$ the hardnesses were significantly higher and strongly influenced by travel speed. The higher the travel speed, the higher the hardness, with peaks at the stir zone edges. As in the previous work, ${ }^{2}$ the transverse tensile tests all failed in the parent plate. Longitudinal tensile tests showed that, compared to the base material, the weld metal had very significant increases $(\sim 40 \%)$ in yield and tensile strength, and that travel speed was influencing those properties, too. At this stage of the development, there was a significant lack of toughness and fatigue data. The issue about travel speed increase leading to higher strength and poorer elongation was confirmed in a subsequent publication ${ }^{4}$ where toughness results were presented. These data showed that DH36 steel was achieving $<27 \mathrm{~J}$ at $-30^{\circ} \mathrm{C}$, but that high strength low alloy (HSLA) 65 had the potential to develop higher toughness. However, it appears that the HLSA 65 welds were double sided FSW, whereas the DH36 was a single sided FSW. It is therefore difficult to compare and contrast these data ${ }^{4}$ with other published data due to the lack of process detail. The work on HSLA $65^{4}$ was extended to include a simulation of the FSW process ${ }^{5}$ and its thermomechanical history, primarily using Gleeble testing. However, the work appeared to be of 
limited value at that stage. Further, double sided FSW were produced at thicknesses of $16-19 \mathrm{~mm}$ for a linepipe evaluation. Hardness could be as high as $310 \mathrm{HV}$, and this tended to be coincident with areas containing martensite or bainite. As in the previous work, ${ }^{4}$ there were much higher strengths in the longitudinal tensile test results. However, there tended to be low toughness in the stir zone, but there was an opinion that the parent plate material was a contributor to the poor stir zone toughness.

Konkol and Mruczek $^{6}$ compared FSW and SAW (submerged arc weld) of X65 grade steel. The overall conclusions were that the friction stir material had more uniform hardness than the SAW; the distortion was less in the FSW than in the SAW on $6 \mathrm{~mm}$ thick plate; although the stir zone toughness in the HAZ was superior in the FSW, there was overall not much difference in toughness in the HAZ areas. There was one bend test failure that was attributed to tool material becoming embedded into the weld region. Based on these data, there was scope for the FSW process to be viable for X65. Some work ${ }^{7}$ was carried out on a rolled, quenched and tempered 701 grade steel, which has a broadly similar chemistry to DH36 but a completely different structure. The outcomes were that there was very little difference in the residual stresses generated between single pass and double pass FSW welding and that there was a slight tendency to produce higher hardness regions in the area of stir zone associated with the edge of the tool position.

Work carried out on high carbon tool steel yielded some useful data. ${ }^{8}$ When welding was carried out below the $A_{1}$ transformation temperature, no martensite was formed and there was a better combination of strength/ toughness when welding was carried out below the $A_{1}$ temperature compared to that welded above it.

An in-depth microstructural investigation was carried out by Ozekchin et $a l^{9}{ }^{9}$ on X80 steel, which has a chemical composition not too dissimilar from DH36, apart from the addition of molybdenum $(0 \cdot 17 \%)$ and vanadium $(0 \cdot 062 \%)$ instead of niobium. A peak hardness of 350 was found in the stir zone towards one side, which was the advancing side of the tool. The macrosample showed that there was a different etching response in that area. In the HAZ area, there was some evidence of a feature termed reverted austenite, but the extent of its presence was not discussed. The stir zone consisted of granular bainite, upper bainite and lath martensite. Perhaps, the most significant comment made in this work was the absence of contiguous coarse grains at the fusion line in the FSW compared to SAW. Continuation work was reported, ${ }^{1}$ which again highlighted toughness issues. In addition, modelling work showed $^{1}$ that there was an asymmetric strain rate distribution related to the advancing side of the weld, and this in turn seemed to be related to an asymmetric model prediction of the peak temperature. Some of the actual hardness measurements also showed an asymmetric effect, again towards the advancing side. A reasonable number of the hardness measurements were in the range $290-350$.

In summary, the mechanical properties were strongly controlled by the FSW process parameters, and that properties such as toughness and elongation were variable in most cases. The double sided process appeared to improve properties, but at present, this is a relatively tenuous comment.

\section{Experimental}

The plate material studied in this work was shipbuilding grade DH36 steel plate, and the specific plates used were selected at random. Thickness was 4, 6 and $8 \mathrm{~mm}$, and the chemical analysis of each plate is shown in Table 1 . The $4 \mathrm{~mm}$ thick plate was sourced from a different mill to the 6 and $8 \mathrm{~mm}$ and, as a result, developed the plate properties in a different manner. Based on the sample used, it has a less banded structure than the 6 and $8 \mathrm{~mm}$ thick plate. The plates were chosen on the basis of material that potentially would be used in actual construction. In the past, a thick plate has been used and milled down to different thicknesses, but this resulted in non-optimum chemistry being used plus the inability to be fully confident that the distortion produced would be representative of the rolled product and not a rolled and milled product.

Each plate had been shot blasted and primed before being cut, from a mother plate, using a laser cutting process. All welding took place in a direction parallel to the main rolling direction. Plate mechanical properties have been shown in Table 2. These are based on the plate mill certificates.

All the welding was carried out from one side, but an additional $8 \mathrm{~mm}$ thick plate was also welded from two sides for limited comparative purposes, and also to act as an aid to indicate possible directions of future research.

As a comparison, conventional double sided SAWs were produced to demonstrate the current base case against which FSW would be compared.

Table 1 Parent plate and weld metal chemical analysis (calculated heat input for each weld is based on equations shown below)*/wt-\%

\begin{tabular}{|c|c|c|c|c|c|c|c|c|c|c|}
\hline Plate thickness/mm & & C & $\mathrm{Si}$ & $\mathrm{Mn}$ & $P$ & $\mathrm{~s}$ & Al & $\mathrm{Nb}$ & $\mathrm{N}$ & Heat input/kJ mm $\mathrm{mm}^{-1}$ \\
\hline & Parent plate & $0 \cdot 14$ & $0 \cdot 37$ & $1 \cdot 34$ & $0 \cdot 017$ & $0 \cdot 008$ & 0.01 & 0.03 & 0.003 & \\
\hline \multirow[t]{3}{*}{8} & FSW weld area & $0 \cdot 15$ & $0 \cdot 38$ & $1 \cdot 35$ & $0 \cdot 016$ & 0.008 & $0 \cdot 01$ & 0.03 & 0.003 & $3 \cdot 23$ \\
\hline & SAW weld area & $0 \cdot 11$ & $0 \cdot 46$ & 1.5 & 0.018 & 0.008 & $<0.01$ & 0.002 & 0.004 & $4 \cdot 38$ \\
\hline & Parent plate & $0 \cdot 11$ & $0 \cdot 37$ & $1 \cdot 48$ & 0.014 & 0.004 & 0.02 & $0 \cdot 02$ & 0.002 & \\
\hline \multirow[t]{3}{*}{6} & FSW weld area & $0 \cdot 12$ & $0 \cdot 37$ & $1 \cdot 49$ & $0 \cdot 014$ & 0.004 & 0.02 & 0.02 & 0.003 & $3 \cdot 08$ \\
\hline & SAW weld area & 0.09 & 0.52 & $1 \cdot 62$ & $0 \cdot 017$ & 0.006 & $<0.01$ & 0.01 & 0.003 & $3 \cdot 79$ \\
\hline & Parent plate & 0.09 & $0 \cdot 21$ & $1 \cdot 35$ & 0.021 & $0 \cdot 01$ & 0.02 & $<0.01$ & 0.002 & \\
\hline \multirow[t]{2}{*}{4} & FSW weld area & 0.09 & $0 \cdot 2$ & $1 \cdot 34$ & 0.021 & $0 \cdot 1$ & 0.02 & $<0.01$ & 0.002 & $2 \cdot 68$ \\
\hline & SAW weld area & 0.08 & 0.55 & $1 \cdot 67$ & $0 \cdot 022$ & 0.009 & 0.02 & $<0.01$ & 0.003 & $2 \cdot 88$ \\
\hline
\end{tabular}

*FSW heat input $=\varepsilon 2 \pi r T / 1000 \mathrm{~V}\left(\mathrm{~kJ} \mathrm{~mm}^{-1}\right), \varepsilon$ dimensionless factor indicative of process efficiency, $r$ rotation speed $\left(\right.$ rev min $\left.{ }^{-1}\right), T$ average steady state spindle torque $(\mathrm{N} \mathrm{m}), v=$ traverse speed $\left(\mathrm{mm} \mathrm{min}^{-1}\right)$, SAW heat input $=V A 60 / 1000 v\left(\mathrm{~kJ} \mathrm{~mm}^{-1}\right), V$ voltage $(V), A$ current (A), $v$ traverse speed $\left(\mathrm{mm} \mathrm{min}^{-1}\right)$. 


\section{Processing details and outcomes}

Submerged arc welding was carried out using a $3.2 \mathrm{~mm}$ diameter solid wire. The heat inputs were calculated on the basis of the equations shown in Table 1 . No allowance has been made for arc efficiency. If anything, the FSW arc efficiency should be lower than the SAW, as the FSW is exposed to the atmosphere and subject to an inert gas being used to cool the tool.

Each of the welded plates was assumed to be flat before welding, and visual inspection of them showed that they were all relatively flat. After welding, the welded plates were laser scanned to produce the welded plate profile. The profiles are shown in Fig. $1 b, d$ and $f$ for the FSW and Fig. $1 a, c$ and $e$ for the SAW.

It is quite clear that the FSW process induced significantly less distortion than did the SAW process. In both cases, the extent of distortion decreased as the thickness increased, as expected. A summary of the distortion data is shown in Table 3 using the difference between the minimum and maximum distortion as the assessment. While the $4 \mathrm{~mm}$ thick FSW had the lowest calculated heat input in the data shown in Table 1, it also had the greatest distortion of the FSW plates. If the calculated heat input is divided by the plate thickness, then the $4 \mathrm{~mm}$ plate has, in theory, the highest heat input $/ \mathrm{mm}^{2}$. The figures are shown below.

Each plate was X-rayed and all the material, SAW and FSW, was defect free.

Macrosamples of each weld were taken, and in the case of the FSW material, the identities of the advancing and retreating edges of the stir tool were maintained.

All the macros are shown in Fig. $2 a-d$ for FSW and Fig. $2 e-g$ for SAW. In the FSW welds, there were no glaringly obvious swirl patterns that have been reported elsewhere ${ }^{3}$ and are apparently associated with variations on stir zone hardness. There was a slight swirl on the retreating side of the $8 \mathrm{~mm}$ single sided of the FSW plate. In addition, full penetration welding has been achieved for each thickness. There was a progressive increase in the top surface width of the stir zone with increase in plate thickness. Each of the parent plates and weld metals were chemically analysed to assess differences in the chemical compositions. This is shown in Table 1. As would be expected, the SAW weld metal was significantly different to the parent plate due to the composition of the filler wire and the dilution effects from the parent plate. The most prominent differences were in the carbon, silicon and manganese contents. In the case of the FSW material, there were only minor differences in the chemical composition of the stir zone compared to the parent plate, which would be expected.

\section{Properties}

Before testing, the flash at the outer edge of the friction stir weld zone was lightly ground to remove it. In each of the welds produced, this flash was classed as being light.
Weld region hardness was evaluated using a Zwick/ Roell ZHV-Indentec automated hardness scanner (ST 2000 Stage Controller) with a load of $1 \mathrm{kgf}$ and an indenter grid spacing of $\sim 300 \mu \mathrm{m}$. Pictorial representations of the weld region hardness surveys are shown in Fig. $3 a$ for FSW and Fig. $3 b$ for SAW.

All the transverse tensile testpieces fractured in the parent plate, which is in line with the previous findings. ${ }^{2}$

To assess stir zone toughness, a series of Charpy tests were carried out across the welds. From the weld centreline, three additional tests were carried out on each side at $2 \mathrm{~mm}$ intervals on the FSW, while identifying, advancing and retreating edges of the specimens. The $2 \mathrm{~mm}$ increments meant that 4 and $6 \mathrm{~mm}$ thick weld samples were composed entirely of stirred material, but the $8 \mathrm{~mm}$ thick weld contained a very small proportion of parent plate, which was almost equivalent on either side of the weld centreline. For comparison purposes, the same was carried out for the SAW welds, although no side to side variations were anticipated. The specimens were different sizes dependent on plate thickness. The data shown in Table 4 have normalised all the Charpy data to a $10 \times 10 \mathrm{~mm}$ equivalent using the conventions adopted in Lloyds Naval Rules. There is, however, no factor for the $2.5 \mathrm{~mm}$ samples used for the $4 \mathrm{~mm}$ thick plates, but a factor of 2 has been adopted, as being broadly in line. All tests were carried out at $-20^{\circ} \mathrm{C}$, in line with the current requirements in Lloyds Naval Rules. For commercial vessels, this requirement would be $0^{\circ} \mathrm{C}$ with a minimum impact requirement of $34 \mathrm{~J}$. Clearly, there is not an issue with the toughness of the weld zones in either the SAW or the FSW. Overall, there is very little difference between the single sided FSW and SAW, but the double sided $8 \mathrm{~mm}$ thick FSW has significantly better toughness than any of the other samples, a fact that was discussed earlier. ${ }^{4}$

Root and face bend tests were all satisfactory, but some subsequent uncompleted work has shown that small tears can occur, which coincide with the tool stir marks on the surface of the weld. There will require a definition of a surface preparation and finishing standard for FSW bend testpieces.

\section{Microstructure}

Each sample was examined at mid-thickness in the weld metal, HAZ and parent plate as shown in Fig. 4. All work was carried out at a magnification of $\times 500$ to be sure of the detail of the microstructure. The centre weld metal of the FSW samples was relatively similar, with a uniform acicular ferrite microstructure. It did appear that as the thickness decreased, then a finer structure was produced. A higher magnification scanning electron microscopy (SEM) image in Fig. $5 a$ shows the regularity of the structure, which appears to be finer than that reported by Lienert et $a l^{2}$ The exact nature of this structure has not been determined and will be the subject

Table 2 Mechanical properties of plates used for SAW and FSW welding trials

\begin{tabular}{llll}
\hline Plate thickness $/ \mathbf{m m}$ & Ultimate tensile strength/N mm & Yield strength/N mm & Elongation/\% \\
\hline 8 & 558 & 395 & $26 \cdot 5$ \\
6 & 541 & 470 & 27 \\
4 & 490 & 415 & 29 \\
\hline
\end{tabular}


(a)

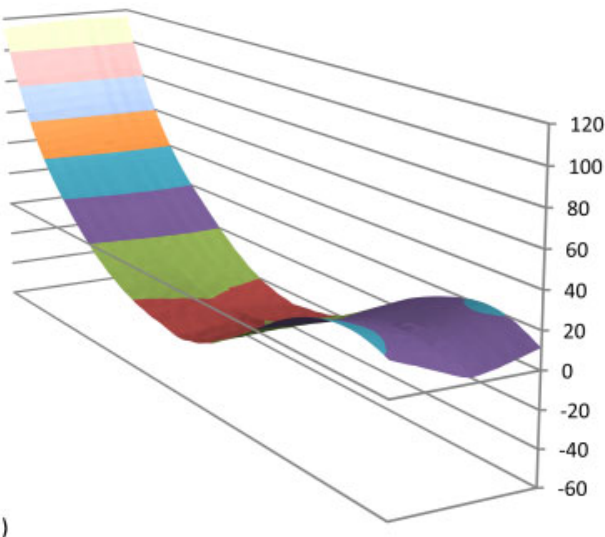

(c)

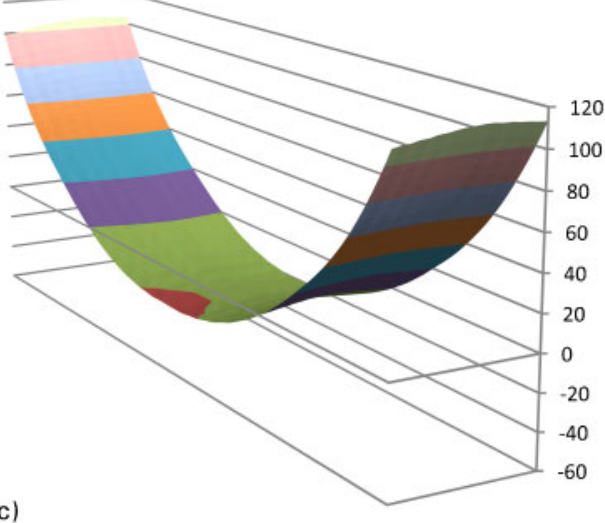

(e)

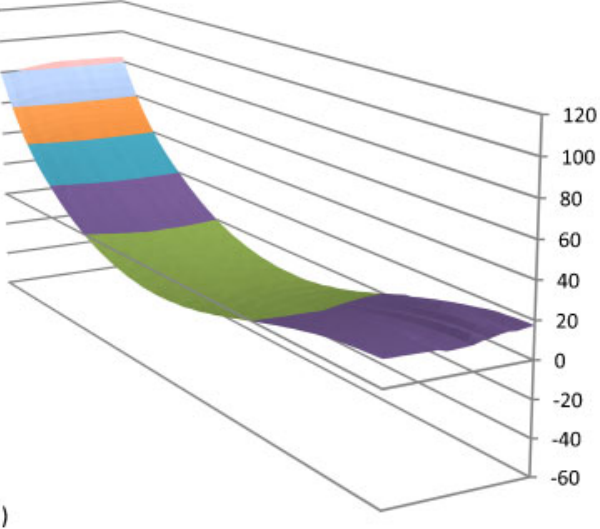

$=100-12$

$=80-100$

$=60-80$

$=40-60$

= 20-40

= $0-20$

II $-20-0$

|- $-40-20$

- $-60--40$

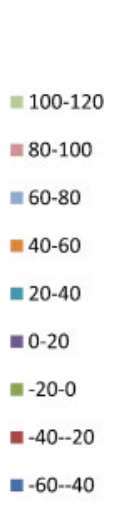

$=-60--40$

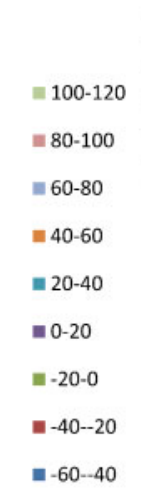

$=5-15$

= -5-5

$=-15-5$

$=-25-15$

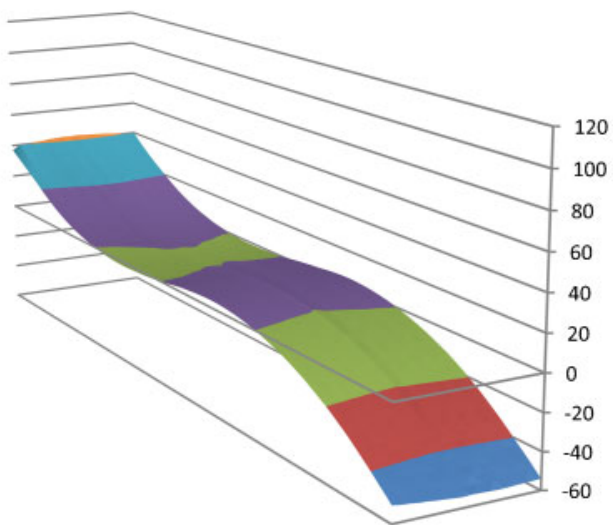

$=100-120$

$=80-100$

$=60-80$

$=40-60$

= $20-40$

- $0-20$

$=-20-0$

= $-40--20$

= - $-60--40$

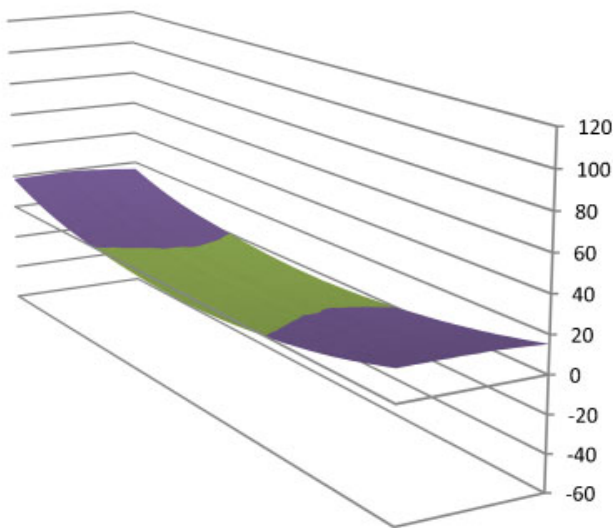

(b)

$=100-120$

$=80-100$

$=60-80$

$=40-60$

- 20-40

- $0-20$

$=-20-0$

= $-40--20$

- $-60-40$

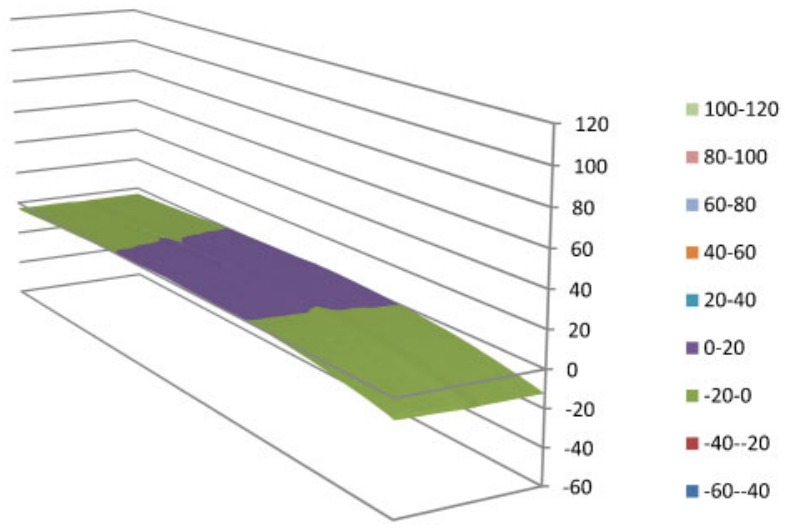

(f)

(g)

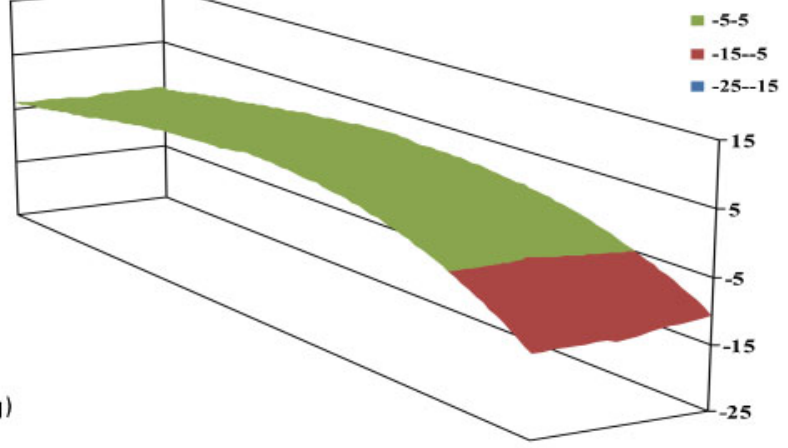

a $4 \mathrm{~mm}$ submerged arc; $b 4 \mathrm{~mm}$ friction stir; c $6 \mathrm{~mm}$ submerged arc; $d 6 \mathrm{~mm}$ friction stir; e $8 \mathrm{~mm}$ submerged arc; $f$ $8 \mathrm{~mm}$ friction stir; $g 8 \mathrm{~mm}$ FSW double sided

1 Distortion profiles for all plates welded (all readings are in $\mathrm{mm}$; plate length is $2000 \mathrm{~mm}$; welded plate width is $400 \mathrm{~mm}$ )

of another investigation. An initial evaluation of the overlap region of a double sided FSW sample was carried out. This showed a finer structure in the overlap region, and the grain structure was generally less acicular in nature, as shown in Fig. $5 b$. Swirl patterns in this area had similar microstructures, but again, there is significant scope for more work in characterising these regions. Initial grain size measurements showed the 


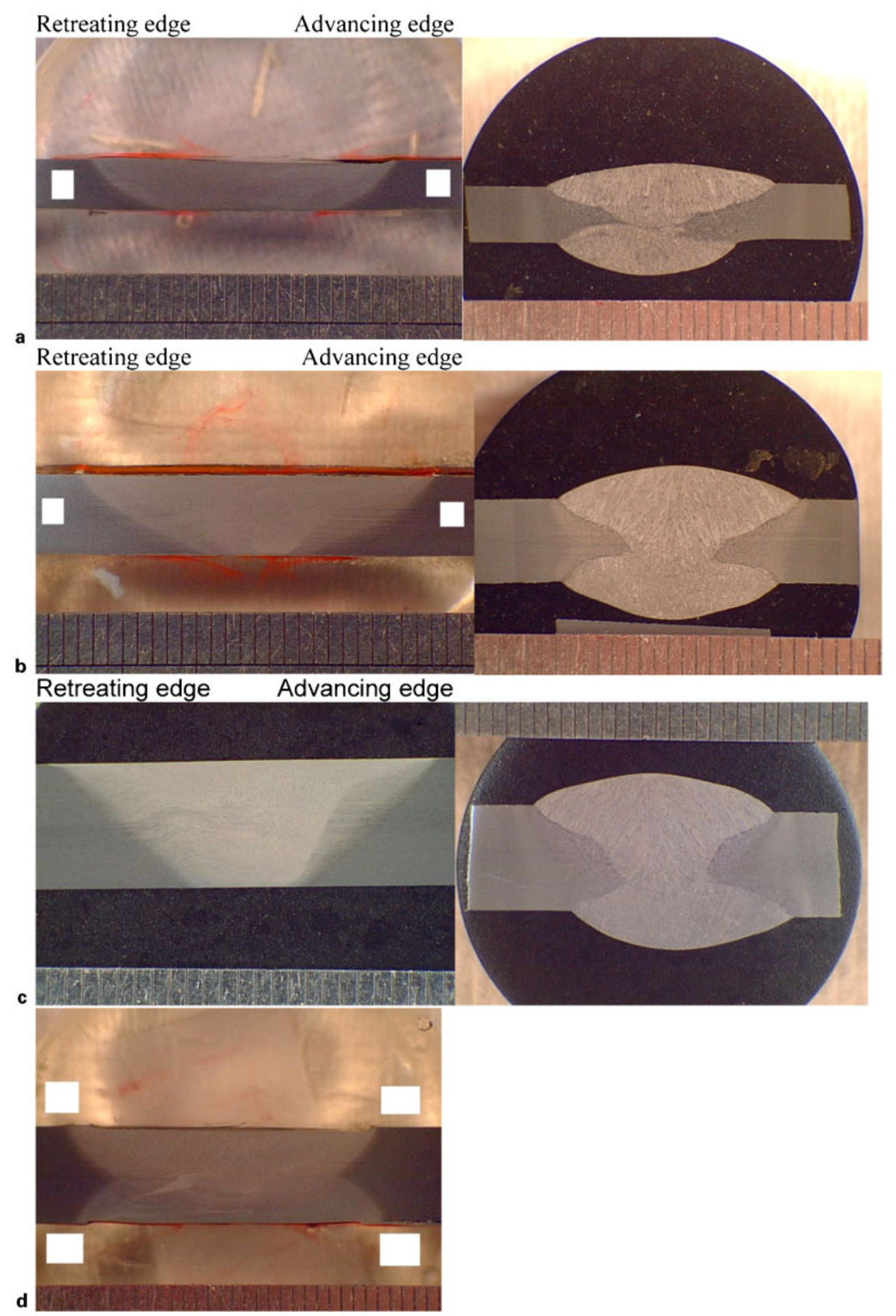

a $4 \mathrm{~mm}$ thick single sided FSW and double sided SAW; $b 6 \mathrm{~mm}$ thick single sided FSW and double sided SAW; $c 8 \mathrm{~mm}$ thick single sided FSW and double sided SAW; $d 8 \mathrm{~mm}$ thick double sided FSW

2 Macrosamples for all welded plates

Table 3 Distortion as function of plate thickness and weld process*

\begin{tabular}{llll}
\hline & $\begin{array}{l}\text { Distortion over } \\
2000 \mathrm{~mm} \text { double } \\
\text { sided SAW plates/mm }\end{array}$ & $\begin{array}{l}\text { Distortion over } \\
2000 \mathrm{~mm} \text { single } \\
\text { sided FSW plates } / \mathrm{mm}\end{array}$ & $\begin{array}{l}\text { Distortion over } \\
2000 \mathrm{~mm} \text { double } \\
\text { sided FSW plates } / \mathrm{mm}\end{array}$ \\
\hline 8 & 80 & 15 & 10 \\
6 & 110 & 20 & \\
4 & 120 & 60 & \\
\hline
\end{tabular}

*8 mm: $0.40 \mathrm{~kJ} \mathrm{~mm}^{-2} ; 6 \mathrm{~mm}: 0.51 \mathrm{~kJ} \mathrm{~mm}^{-2} ; 4 \mathrm{~mm}: 0.62 \mathrm{~kJ} \mathrm{~mm}^{-2}$ 


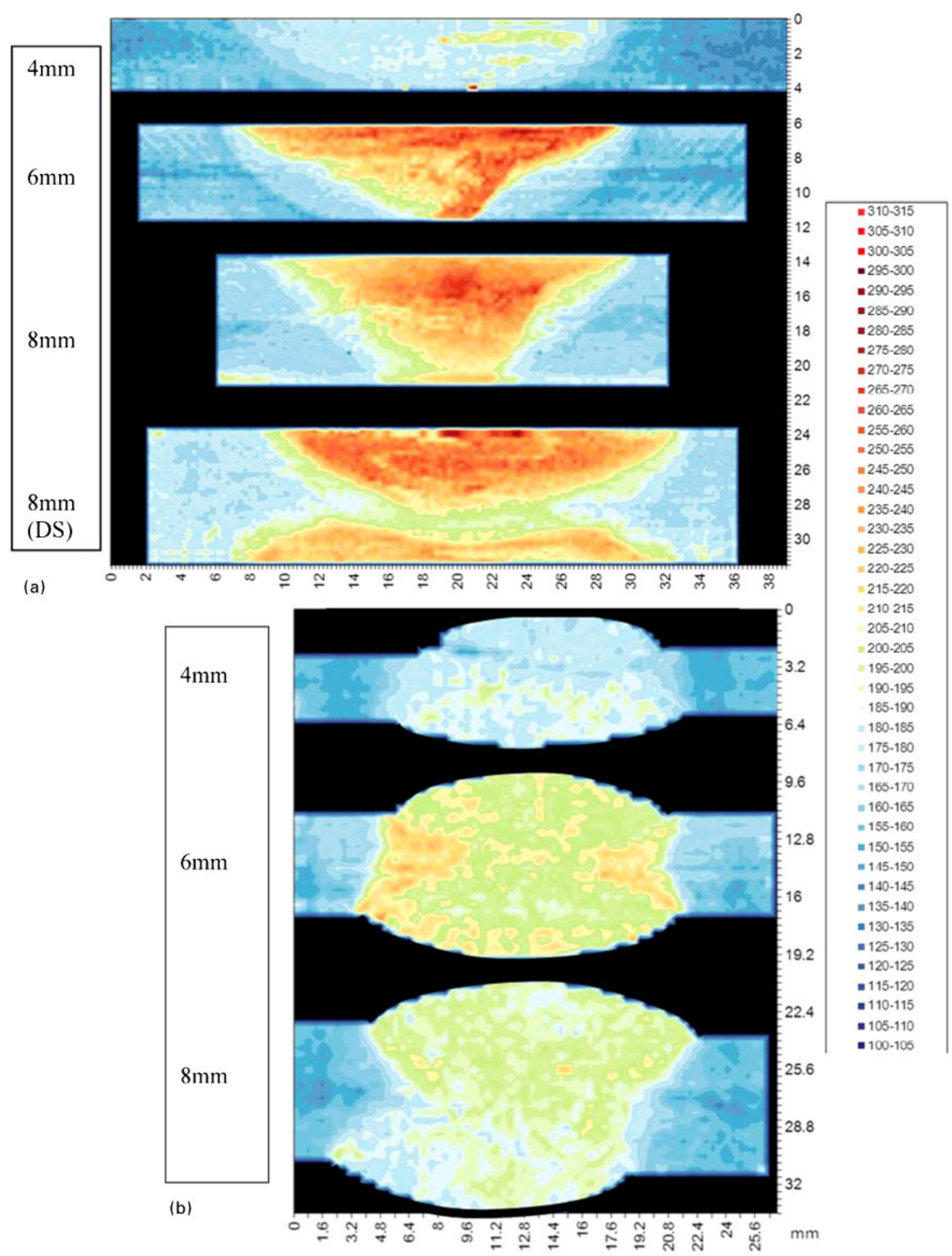

$3 a$ hardness profiles for all FSW welds produced and $b$ hardness profiles for all SAW welds produced Table 4 Toughness data at $-20^{\circ} \mathrm{C}$ for all welds*

\begin{tabular}{|c|c|c|c|c|c|c|c|c|c|}
\hline \multirow[b]{2}{*}{$\begin{array}{l}\text { Plate } \\
\text { thickness } / \mathrm{mm}\end{array}$} & & \multirow[b]{2}{*}{$\begin{array}{l}\text { Single/double } \\
\text { sided weld }\end{array}$} & \multirow{2}{*}{$\begin{array}{l}\text { Weld metal } \\
\text { CL }\end{array}$} & \multirow[b]{2}{*}{$+2 \mathrm{mmA}$} & \multirow[b]{2}{*}{$+4 \mathrm{mmA}$} & \multirow[b]{2}{*}{$+6 \mathrm{mmA}$} & \multirow[b]{2}{*}{$+2 \mathrm{mmR}$} & \multirow[b]{2}{*}{$+4 \mathrm{mmR}$} & \multirow[b]{2}{*}{$+6 \mathrm{mmR}$} \\
\hline & & & & & & & & & \\
\hline 8 & FSW weld area & Double & 157 & 103 & 167 & 125 & 161 & 156 & 170 \\
\hline \multirow[t]{2}{*}{8} & FSW weld area & Single & $73 \cdot 2$ & $70 \cdot 8$ & 48 & $52 \cdot 8$ & $68 \cdot 4$ & $46 \cdot 8$ & $50 \cdot 4$ \\
\hline & SAW weld region & Double & $64 \cdot 8$ & $74 \cdot 4$ & 54 & 41 & 132 & 48 & 36 \\
\hline \multirow[t]{2}{*}{6} & FSW weld area & Single & $115 \cdot 5$ & $79 \cdot 5$ & 51 & 111 & $85 \cdot 5$ & 72 & 132 \\
\hline & SAW weld region & Double & 93 & $94 \cdot 5$ & $94 \cdot 5$ & 114 & $46 \cdot 5$ & 69 & $118 \cdot 5$ \\
\hline \multirow[t]{2}{*}{4} & FSW weld area & Single & 61 & 66 & 62 & 58 & 64 & 58 & 56 \\
\hline & SAW weld region & Double & 46 & 60 & 56 & 72 & 62 & 60 & 60 \\
\hline
\end{tabular}

*8 $\mathrm{mm}$ testpieces were $7.5 \mathrm{~mm}$ and converted to $10 \mathrm{~mm}$ equivalent using a factor of $6 / 5 ; 6 \mathrm{~mm}$ testpieces were $5.0 \mathrm{~mm}$ and converted to $10 \mathrm{~mm}$ equivalent using a factor of $3 / 2 ; 4 \mathrm{~mm}$ testpieces were $2.5 \mathrm{~mm}$ and converted to $10 \mathrm{~mm}$ equivalent using a factor of 2; A, advancing side for FSW; R, retreating side for FSW. 

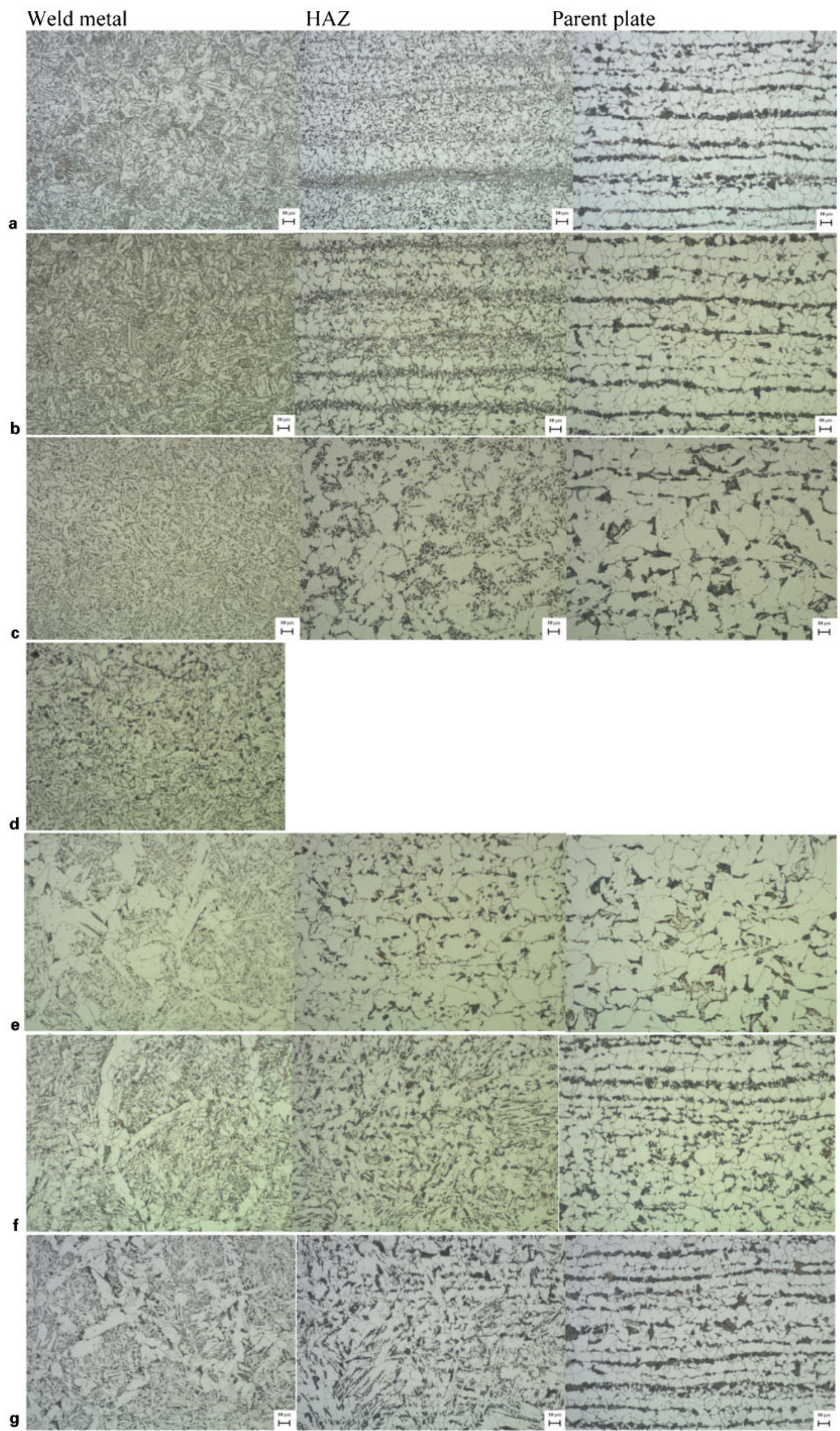

4 a $8 \mathrm{~mm}$ single sided FSW, b $6 \mathrm{~mm}$ single sided FSW, c $4 \mathrm{~mm}$ single sided FSW, d $8 \mathrm{~mm}$ double sided FSW, e $4 \mathrm{~mm}$ thick double sided SAW, $f 6 \mathrm{~mm}$ thick double sided SAW and $g 8 \mathrm{~mm}$ thick double sided SAW 

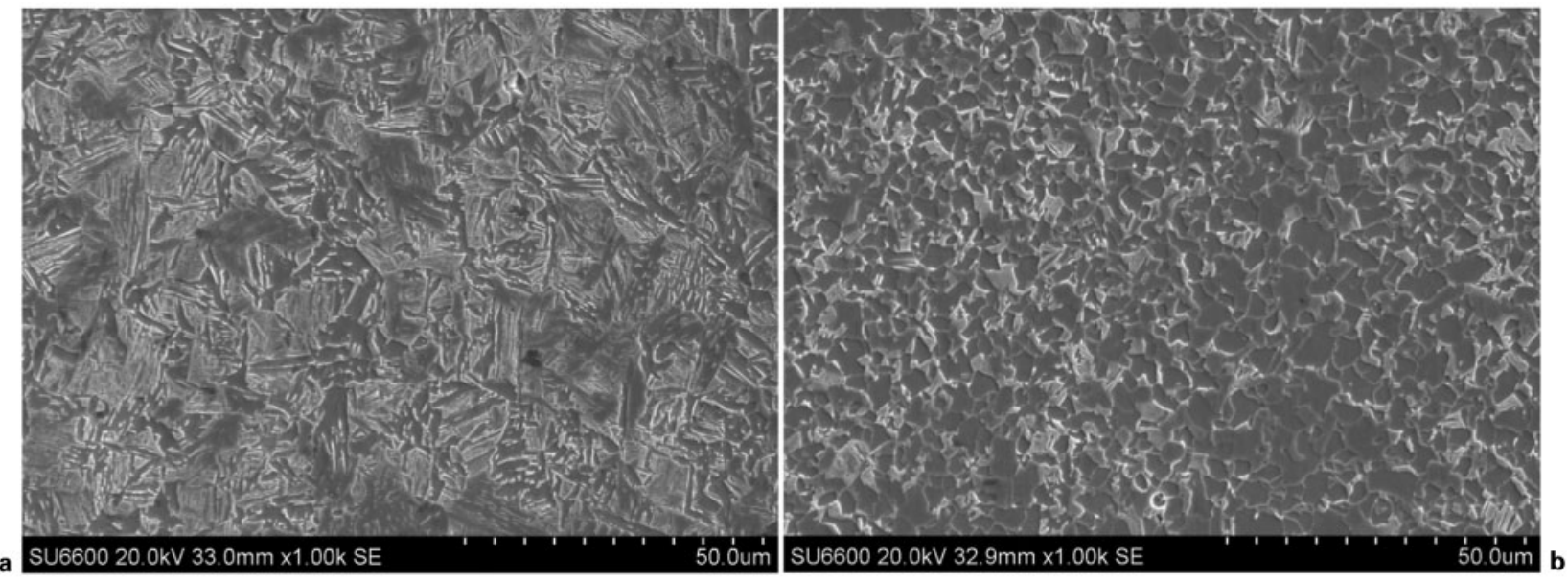

5 Microstructures (SEM) of a main stir zone and $b$ overlap area of stir zones

overlap area to have an average grain size of $2 \cdot 35 \mu \mathrm{m}$, while the stirred regions above and below it were 2.7 and $2.93 \mu \mathrm{m}$ respectively. However, it is really the grain morphology and not the size that is the key issue here. The weld metal of the SAW samples showed the normal acicular ferrite structure outlined by boundaries of proeutectoid ferrite. This might be expected to produce poorer toughness than the FSW microstructure, but the effects of enhanced manganese in solid solution and reduced carbon content would counteract some of the microstructural effects.

The HAZ structure of the FSW is characterised by a breakdown of the pearlite colonies into colonies of small pearlite granules. This is irrespective of whether it is a banded structure or otherwise that is being looked at or the more regular structure. In the SAW welds, there is less breakdown of the pearlite, although it appears to have decreased in size.

The grain sizes established in this work is very similar to that reported by Cho et al., ${ }^{10}$ although the starting point in that study was a much lower carbon steel, which had a ferrite-bainite structure. This specific work did highlight the need to more fully understand the processes of recrystallisation and recovery within the overall stirring process.

The parent plates in the present study were typical of most rolled product with an element of banding being seen on them. The $4 \mathrm{~mm}$ thick plate appeared to have a slightly different distribution of ferrite pearlite, but the processing mill has a relatively unique mill configuration for plate steels of this thickness.

\section{Hardness}

The three SAW specimens all had very acceptable levels of hardness, which were not out with the norm expected from this process. In addition, the weld hardness was reasonably symmetrical in the transverse direction. The single sided FSW welds all had an asymmetric hardness distribution, which appeared to be associated with the advancing edge of the tool. This is particularly evident on the $6 \mathrm{~mm}$ thick sample in Fig. 3a. In turn, this could be associated with the difference in relative material movement direction and thus localised strain rates from one side of the tool to the other, which will influence heat generation from adiabatic shear. The modelling

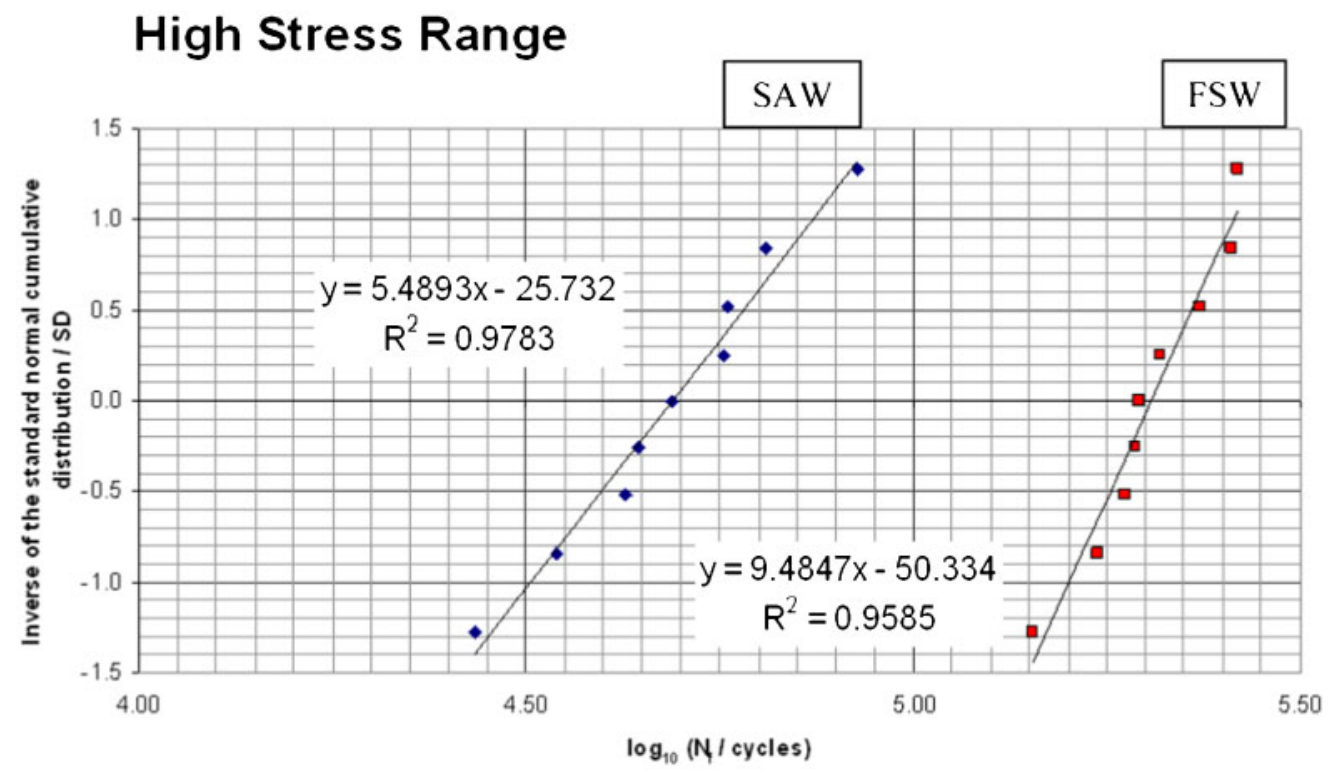

6 Comparison between SAW and FSW fatigue testing for all thickness of welds produced 


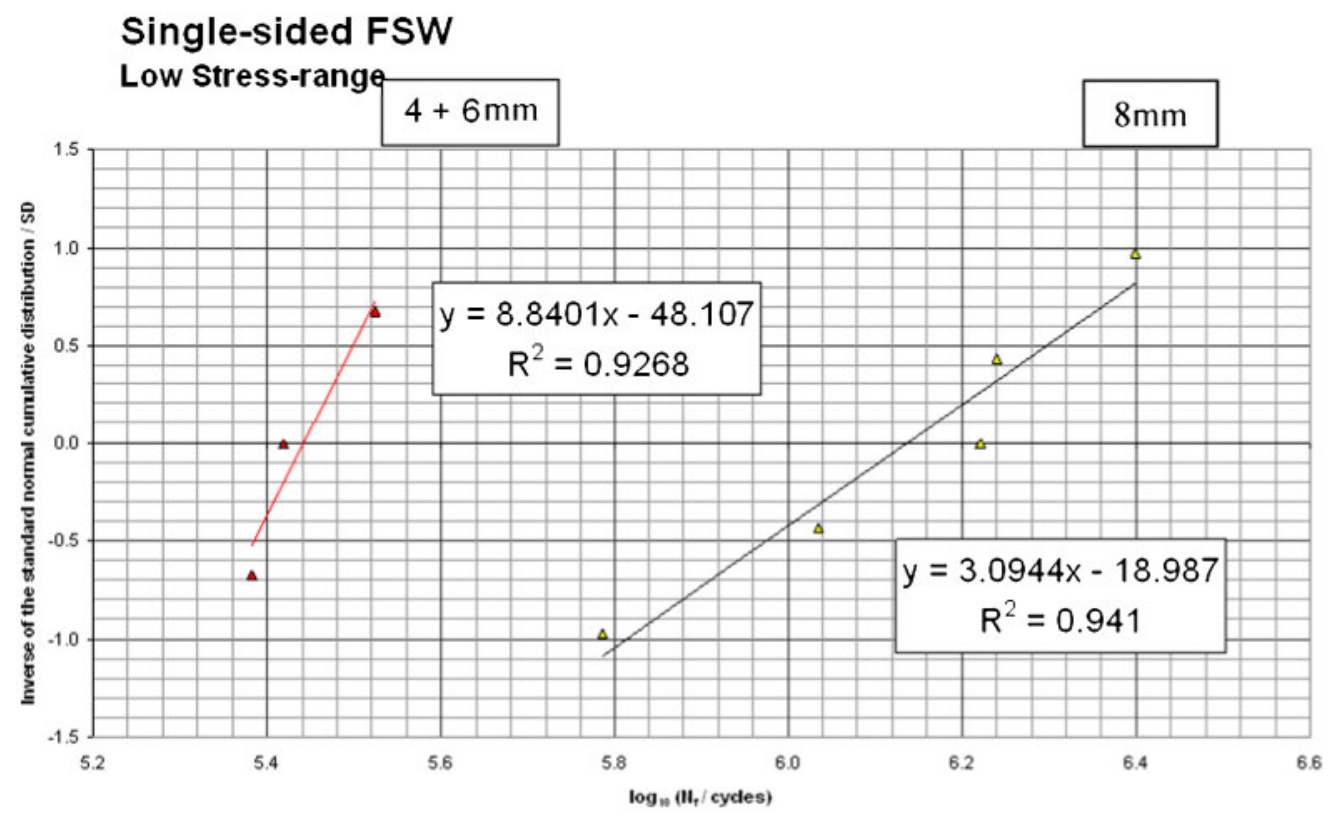

7 Comparison between $8 \mathrm{~mm}$ thick and 4 and $6 \mathrm{~mm}$ thick single sided FSW fatigue testing

work of Fairchild et al. ${ }^{1}$ identified such asymmetric effects as being related to the strain rate and maximum temperature within the weld. There was also evidence to show that differences in hardness could be delineating some of the swirl patterns. This is particularly obvious in the double sided FSW in Fig. $3 a$. However, it is essential to recognise that although differences are being debated, these differences are not major and do not constitute a potential problem in the FSW welds. In addition, the maximum hardness range in the current welds was not as high as that reported by Fairchild et $a l^{1}$ This could be related to a number of factors or their combinations. For example, the DH36 steels used in this study had much lower carbon equivalent $(0 \cdot 32$ $0 \cdot 38 \%$ ) compared to that reported as $0 \cdot 44 \%$ for the X80 steel. ${ }^{9}$ This would have the effect of increasing the steel hardenability, which could account for the difference in hardness.

\section{Fatigue testing}

Fatigue testing was carried out on both the FSW material and the SAW material.

The samples for fatigue testing were prepared on the outer cut edges only, leaving the weld surfaces unmachined. Two testing regimes were used: low cycle fatigue (LCF) and high cycle fatigue (HCF). Based on the yield stress of the material, the LCF tests were conducted at $95 \%$ of the yield stress, and the HCF tests at $80 \%$ of the yield stress. The stress frequency was constant at $10 \mathrm{~Hz}$, and the stress ranges were $5-50 \cdot 6 \mathrm{KN}$ (mean stress of $27 \cdot 8 \mathrm{KN}$ ) for $\mathrm{LCF}$ and $5-47 \cdot 5 \mathrm{KN}$ (mean stress of $21 \cdot 32 \mathrm{KN}$ ) for HCF. All testing was carried out on an Instron 8802 fatigue testing machine, which had a $500 \mathrm{KN}$ axial force capacity.

Figure 6 compares the FSW single sided welds and the SAW welds at all thicknesses for the high stress range

\section{Friction Stir Welds}

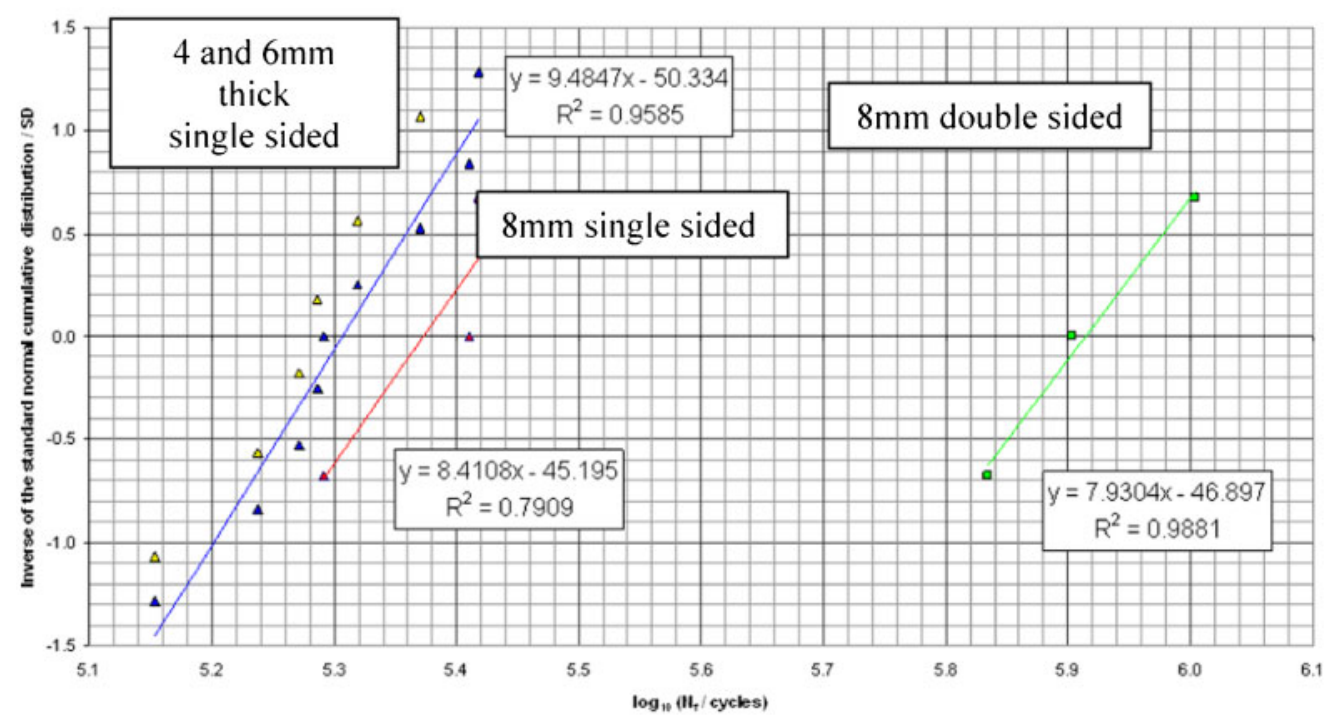

8 Comparison between single sided FSW (all thickness) and double sided FSW (8 mm thick) 


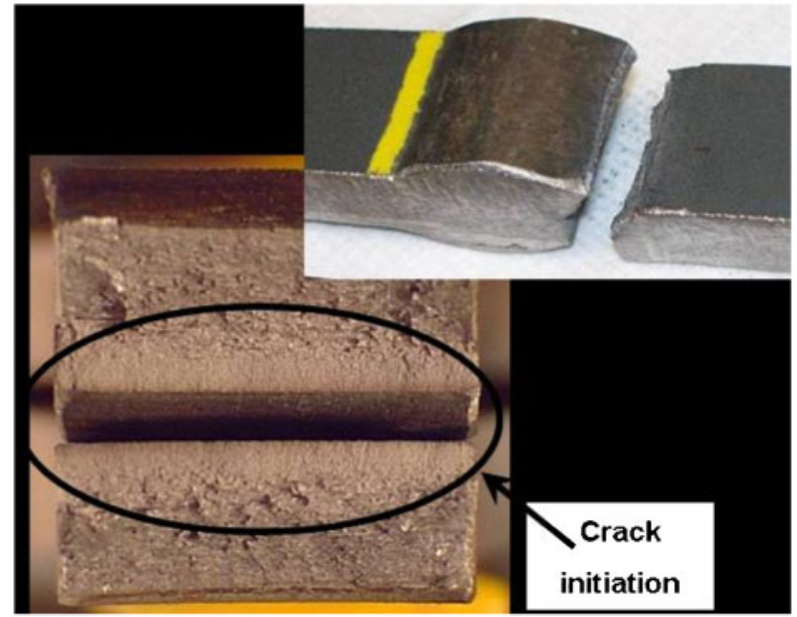

9 Fracture face of SAW fatigue sample

testing condition. The data for the low stress testing range show a similar trend. Statistically, these data have been shown to be robust enough to back up the statement that the FSW welds had better fatigue resistance performance than the SAW samples. These data also showed that the $8 \mathrm{~mm}$ thick single sided FSW had slightly inferior fatigue properties to the combined 4 and $6 \mathrm{~mm}$ data in the low stress range, as shown in Fig. 7.

In addition, a comparison has been made between all the single sided FSW data and the $8 \mathrm{~mm}$ double sided data. Figure 8 shows that fatigue performance of the double sided welds is statistically superior to that of all the single sided data. The reasons for this are not immediately obvious but could be related to residual stress distributions between single and double sided material. Some surface residual stress measurements were carried out but were inconclusive for the three process routes used.

Examination of the fracture faces showed that the SAW fracture initiation point was the transition point on the weld cap to the parent plate, as shown in Fig. 9. The fracture initiation points on the FSW samples were confined to the machining marks left by the tool on the weld nugget surface, as show in Fig. $10 b$ and in the main fracture face in Fig. 10. There is evidence here to show relatively uniform crack growth from each of the tool marks. Figure $10 c$ shows a higher magnification SEM image of the root of the tool mark and the crack propagation below it. Figure $10 d$ shows evidence of ductile fracture in the main fracture face. This part of the work does, however, indicate the need to carefully control the marking left by the tool on the weld surface.

Similar results have been reported on the fatigue testing of FSW aluminium.

\section{Conclusions}

Friction stir welding of shipbuilding quality steel is a viable proposition that will achieve the required mechanical properties of the joint.

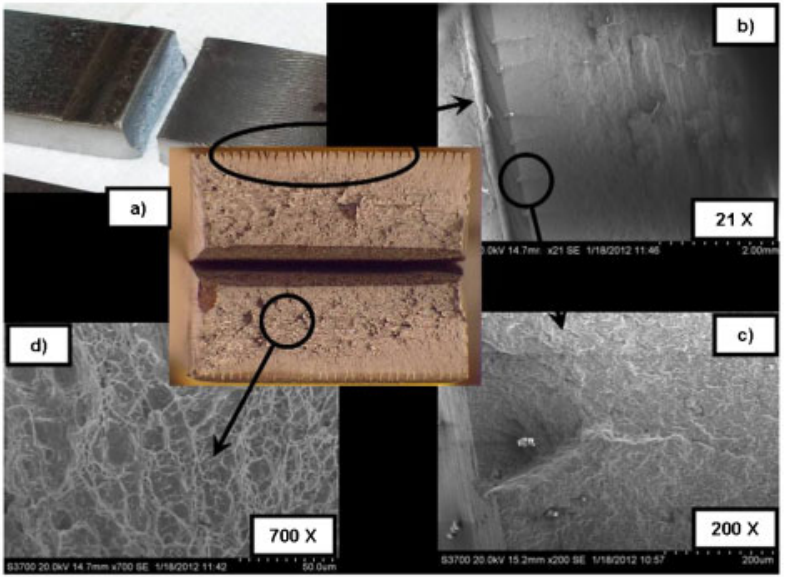

10 Fracture surface of FSW fatigue sample

Friction stir welding is superior to the current SAW in that it produces less distortion, is not detrimental to toughness and does not approach concerning levels of hardness.

In addition, FSW has been shown to produce superior fatigue properties to SAW material.

It appears that double sided friction stir welded DH36 was shown to be superior in all aspects to single sided FSW. This could be related to the smaller grain size effect of the overlap area between the two passes, which is also softer.

\section{Acknowledgement}

The permission of BAE Systems Surface Ships to publish this paper is gratefully acknowledged, as was the analysis of the fatigue data by Colin Davies of Tata Steel Research, Development and Technology.

\section{References}

1. D. Fairchild, A. Kumar, S. Ford, N. Nissley, R. Ayer, H. Jin and A. Ozekchin: Proc. 8th Int. Conf. on 'Trends in welding research', Pine Mountain, GA, USA, June 2008, ASM International, 371380.

2. T. J. Lienert, W. L. Stellwag, B. B. Grimmett and R. Warke: Weld. $J ., 2003,82,1 \mathrm{~s}-9 \mathrm{~s}$.

3. A. P. Reynolds, W. Tang, M. Posada and J. DeLoach: Sci. Technol. Weld. Join., 2003, 8, (6), 455-460.

4. M. Posada, J. P. Nguyen, D. R. Forrest, J. De Loach and R. DeNale: AMPTIAC Q., 2003, 7, (3), 13-20.

5. D. Forrest, J. Nguyen, M. Posada, J. De Loach, D. Boyce, J. Cho and P. Dawson: Proc. 7th Int. Conf. on 'Trends in welding research', Pine Mountain, GA, USA, May 2005, ASM International, 279-286.

6. P. J. Konkol and M. F. Mruczek: Weld. J., 2007, 86, 187-195.

7. S. J. Barnes, A. Steuwer, S. Mahawish, R. Johnson and P. J. Withers: Mater. Sci. Eng. A, 2008, A492, 35-44.

8. Y. D. Chung, H. Fujii, K. Kazuhiro and K. Nogi: Trans. JWRI, 2009, 38, (1), 37-41.

9. A. Ozekchin, H. W. Jin, J. Y. Koo, N. V. Bangura, R. Ayer, G. Vaughn, R. Steel and S. Packer: Int. J. Offshore Polar Eng., 2004, 14, (4), 284-288.

10. H.-W. Cho, S. H. Kang, S.-H. Kim, K. H. Oh, H. J. Kim, W.-S. Chang and H. N. Han: Mater. Des., 2012, 34, 258-267. 